\title{
Role of intestinal microflora in chronic inflammation and ulceration of the rat colon
}

S Videla, J Vilaseca, F Guarner, A Salas, F Treserra, E Crespo, M Antolín, J-R Malagelada

\begin{abstract}
Bacteria and their products stimulate inflammatory responses. The effects of different antimicrobial regimens (amoxicillin/clavulanic acid, tobramycin, imipenem, vancomycin, metronidazole) were investigated on the course of experimental colitis induced by trinitrobenzenesulphonic acid (TNB) in the rat. On day 7 and 21 after the induction of colitis, matched groups of control and antibiotic treated rats were subjected to colonic dialysis to measure eicosanoid release, and killed for morphological assessment of the colonic lesions (macro and microscopic scores). Stool samples were cultured. Selective antibiotic treatment against Gram positive, Gram negative or anaerobic bacteria had no effect on colonic lesion scores. By contrast, certain broad spectrum antibiotics (amoxicillin/clavulanic acid or the association of imipenem plus vancomycin) significantly reduced macro and microscopic scores. Rats receiving these antibiotics did not develop chronic colitis as shown by the virtual absence of colonic strictures, adhesions, fibrosis, and granulomas. On day 21 after TNB, the intracolonic release of prostaglandin $E_{2}$, thromboxane $B_{2}$, and leukotriene $B_{4}$ was significantly higher in control than in antibiotic treated rats. Control stool cultures showed abundant colony forming units of both aerobic and anaerobic bacteria. Amoxicillin/clavulanic acid and imipenem plus vancomycin induced appreciable reductions in luminal bacteria. In conclusion, certain broad spectrum antibiotics prevent chronic colitis. The normal colonic flora seems to play an important pathogenetic part in the progression of inflammatory colonic lesions to chronicity.

(Gut 1994; 35: 1090-1097)
\end{abstract}

The need for a reliable experimental model of inflammatory bowel disease has led to considerable attention being given in recent years to the trinitrobenzenesulphonic acid (TNB) model of intestinal inflammation in the rat. ${ }^{1-10}$ Inflammatory lesions in the distal colon that persist for up to five to six weeks can be induced by a single intracolonic dose of TNB dissolved in ethanol. ${ }^{2}$ Chronic colitis by TNB is characterised by large mucosal ulcerations and transmural inflammation with serosal involvement and adhesions to surrounding tissues. The inflammatory infiltrate consists of both polymorphonuclear and mononuclear cells with occasional granulomas. At high TNB doses, most animals develop colonic strictures that eventually result in voluminous dilatation of the proximal bowel with large chronic ulcers. Spare areas of normal mucosa, however, are seen in the vicinity of the lesions. Thus, the model shows some morphological features that resemble human Crohn's disease.

The mechanism by which TNB induces the lesions is not clear. It was first suggested that TNB acts as an hapten, ${ }^{2}$ as it can modify cell surface proteins by forming covalent bonds with lysine groups. ${ }^{11} \mathrm{~A}$ macrophage mediated response against such modified cells would damage the colonic mucosa triggering the inflammatory reaction. ${ }^{12}$ Subsequent studies have also shown, however, that TNB exerts direct toxicity on intestinal epithelial cell monolayers in vitro without intervention of macrophages. ${ }^{10}$ The metabolism of TNB may yield superoxide and hydrogen peroxide radicals with proinflammatory and cytotoxic properties that could initiate the inflammatory reaction. ${ }^{8}$ Either macrophage mediated cell injury or formation of reactive oxygen species, or both, may thus induce acute inflammation of the rat colon, but these events do not explain the most emblematic peculiarity of the TNB model of colitis - that is, its spontaneous progression to chronicity.

We hypothesised that bacterial antigens present in the colonic lumen could play a part in the development of chronic colitis after TNB. Bacterial cell wall fragments can elicit a response of chronic inflammation when injected into the bowel wall, as shown by Sartor et al. ${ }^{13}$ The intestinal microflora could invade the colonic wall after disruption of the epithelium by the challenge with TNB, and the presence of bacteria would perpetuate the antigenic insult and the inflammatory response within the wall towards chronicity. Thus, the aim of our study was to test this hypothesis by examining the effect of antimicrobial treatment on faecal flora, release of inflammatory mediators, and morphological features of TNB colitis.

\section{Methods}

ANIMALS

Male Sprague-Dawley rats weighing 225 to $250 \mathrm{~g}$ were used in this study. The animals were maintained in a restricted access room with controlled temperature $\left(23^{\circ} \mathrm{C}\right)$ and lightdark cycle (12 h: $12 \mathrm{~h}$ ), and were housed in 
rack mounted cages with a maximum of five rats. Standard rodent chow pellets (Biocenter, Barcelona, Spain) and tap water were provided ad libitum.

\section{EXPERIMENTAL COLITIS}

Chow pellets were withdrawn for 36 hours and rats were given drinking water containing $20 \%$ glucose and electrolytes. On the third day, chow pellets were again permitted. The rats were lightly anaesthetised with ether and colitis was induced by intracolonic instillation of $1 \mathrm{ml}$ of a solution containing $60 \mathrm{mg}$ of 2,4,6-trinitrobenzenesulphonic acid (Carlo Erba, Milan, Italy) in $10 \%$ ethanol (Merck, Darmstadt, Germany) using a rubber cannula ( $8 \mathrm{~cm}$ long, external diameter $2 \mathrm{~mm}$ ) inserted through the rectum. Subsequently, $0.5 \mathrm{ml}$ of air was injected to completely clear the TNB ethanol solution from the cannula.

\section{EXPERIMENTAL DESIGN}

Protocol A: effect of antimicrobials on the acute stage of TNB colitis

Three hundred and fifteen rats were included in this study. All experiments consisted of a test group $(n=15)$ that received antibiotic treatment, and a matched control group $(n=15)$ that received the corresponding vehicle. The following antimicrobial drugs were tested: amoxicillin (160 $\mathrm{mg} / \mathrm{kg}$ per day) plus clavulanic acid ( $40 \mathrm{mg} / \mathrm{kg}$ per day) given twice daily in $5 \mathrm{ml}$ saline enemas (controls received normal saline enemas); tobramycin (2 $\mathrm{mg} / \mathrm{kg}$ per day) plus vancomycin $(50 \mathrm{mg} / \mathrm{kg}$ per day), by enema twice daily; tobramycin (2 $\mathrm{mg} / \mathrm{kg}$ per day), by enema twice daily; metronidazole $(20 \mathrm{mg} / \mathrm{kg}$ per day), by enema twice daily; imipenem ( $50 \mathrm{mg} / \mathrm{kg}$ per day) plus vancomycin ( $50 \mathrm{mg} / \mathrm{kg}$ per day), either by enema twice daily, by intraperitoneal injection twice daily, or orally, diluted in the drinking water as these drugs are not absorbed; vancomycin (50 $\mathrm{mg} / \mathrm{kg}$ per day), in the drinking water; and imipenem $(50 \mathrm{mg} / \mathrm{kg}$ per day), in the drinking water. The volume of water consumed in every cage of rats was measured daily. Addition of drugs did not change the water volume consumed, which averaged $40 \mathrm{ml} /$ day/rat. Drug treatments started three days before TNB and the rats received the same drug up to day 7 after TNB. To test the effect of antibiotic treatment given after the induction of colitis, an additional experiment included a control group and two groups receiving imipenem $(50 \mathrm{mg} / \mathrm{kg}$ ) plus vancomycin $(50 \mathrm{mg} / \mathrm{kg})$ given by mouth. Treatment started either three days before TNB (pre-treatment group) or 24 hours after TNB (post treatment group) and was continued up to day 7 .

In all experiments, weight controls were performed on days 0,3 , and 7 after TNB. On day 7 , the rats were given intracolonic dialysis, and they were then killed by cervical dislocation. The distal colon was removed, opened longitudinally, rinsed with physio- logical saline, and pinned out on synthetic cork. The lesions were assessed macroscopically and the whole piece was then fixed in a solution containing $2 \%$ formaldehyde and $1 \%$ glutaraldehyde for later histological examination.

\section{Protocol B: effect of antimicrobials on the chronic} stage of TNB colitis

Sixty rats were included in this part of the study. The experiments consisted of a test group $(n=15)$ that received antibiotic treatment, and a matched control group $(n=15)$ that received vehicle. The following drugs were tested: amoxicillin (160 $\mathrm{mg} / \mathrm{kg}$ per day) plus clavulanic acid ( $40 \mathrm{mg} / \mathrm{kg}$ per day) given twice daily by intracolonic enema in saline (controls received saline enemas twice daily); and imipenem ( $50 \mathrm{mg} / \mathrm{kg}$ per day) plus vancomycin (50 $\mathrm{mg} / \mathrm{kg}$ per day), diluted in the drinking water. Treatment started three days before the induction of colitis and was continued up to day 7 after TNB. Thereafter, no treatment was given up to day 21 , which was the end point of the experiments. The rats were then given intracolonic dialysis, and killed by cervical dislocation. Colons were exposed, scored macroscopically, and processed for histological assessment as above.

\section{ASSESSMENT OF COLONIC LESIONS}

The macroscopically visible damage was assessed with a stereomicroscope by two

TABLE I Morphological criteria for assessment of colonic damage

\begin{tabular}{|c|c|}
\hline & $\begin{array}{l}\text { Macroscopic } \\
\text { score }\end{array}$ \\
\hline $\begin{array}{l}\text { Adhesions } \\
\text { None } \\
\text { Minimal } \\
\text { Involving several bowel loops }\end{array}$ & $\begin{array}{l}0 \\
1 \\
2\end{array}$ \\
\hline $\begin{array}{l}\text { Strictures } \\
\text { None } \\
\text { Mild } \\
\text { Severe, proximal dilatation }\end{array}$ & $\begin{array}{l}0 \\
2 \\
3\end{array}$ \\
\hline $\begin{array}{l}\text { Ulcers } \\
\text { None } \\
\text { Linear ulceration }<1 \mathrm{~cm} \text { length } \\
\text { Two linear ulcers }<1 \mathrm{~cm} \\
\text { More sites of ulceration or one large } \\
\text { ulcer }>1 \mathrm{~cm}\end{array}$ & $\begin{array}{l}0 \\
1 \\
2 \\
3\end{array}$ \\
\hline $\begin{array}{l}\text { Wall thickness } \\
\text { Less than } 1 \mathrm{~mm} \\
1-3 \mathrm{~mm} \\
\text { More than } 3 \mathrm{~mm} \\
\text { Maximum possible score }\end{array}$ & $\begin{array}{r}0 \\
1 \\
2 \\
10\end{array}$ \\
\hline & $\begin{array}{l}\text { Histological } \\
\text { score }\end{array}$ \\
\hline $\begin{array}{l}\text { Ulceration } \\
\text { No ulcer, epithelisation } \\
\text { Small ulcers }<3 \mathrm{~mm} \\
\text { Large ulcers }>3 \mathrm{~mm}\end{array}$ & $\begin{array}{l}0 \\
1 \\
2\end{array}$ \\
\hline $\begin{array}{l}\text { Inflammation } \\
\text { None } \\
\text { Mild } \\
\text { Moderate } \\
\text { Severe }\end{array}$ & $\begin{array}{l}0 \\
1 \\
2 \\
3\end{array}$ \\
\hline $\begin{array}{l}\text { Depth of the lesion } \\
\text { None } \\
\text { Submucosa } \\
\text { Muscularis propria } \\
\text { Serosa }\end{array}$ & $\begin{array}{l}0 \\
1 \\
2 \\
3\end{array}$ \\
\hline $\begin{array}{l}\text { Fibrosis } \\
\text { None } \\
\text { Mild } \\
\text { Severe } \\
\quad \text { Maximum possible score }\end{array}$ & $\begin{array}{r}0 \\
1 \\
2 \\
10\end{array}$ \\
\hline
\end{tabular}




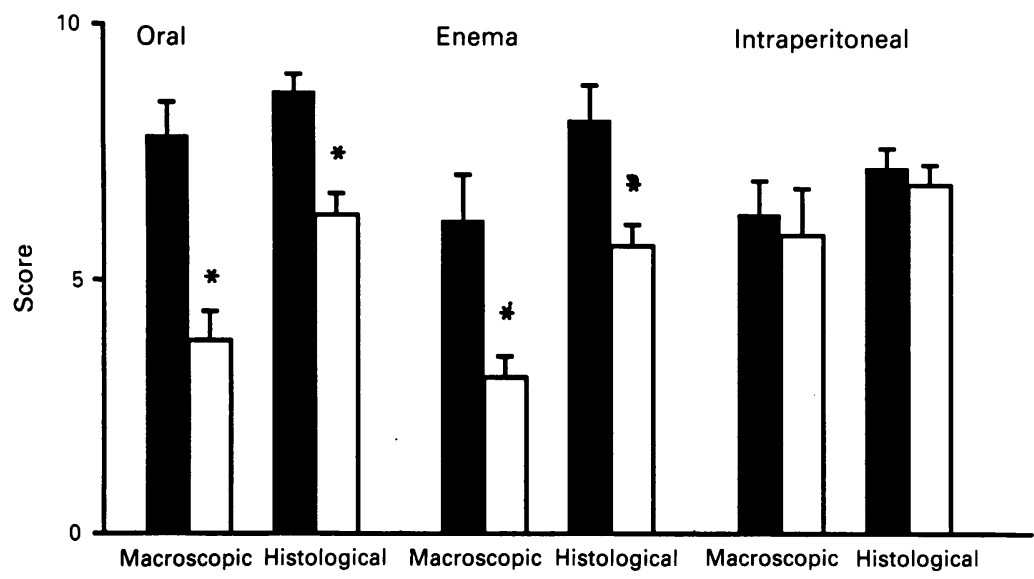

Figure 1: Effect of antibiotic treatment on colonic lesion scores in the acute stage of TNB induced colitis (day 7 after TNB). Scores were obtained according to the criteria shown in Table I. Imipenem plus vancomycin treated rats (open bars) exhibited significantly lower macroscopic and histological lesion scores than controls (solid bars) when treatment was given either orally or by enema $\left({ }^{*} p<0.05 \mathrm{v}\right.$ controls). In contrast, intraperitoneal injection of the antimicrobials was not effective. No mortality was seen in rats treated with these antibiotics, and a single rat from each control group died.

observers unaware of the treatment (JV and FG). Each colon was assigned a score on a scale ranging from 0 to 10 based on the criteria stated in Table I, which include colonic adhesions to surrounding tissues, strictures, mucosal ulcerations, and wall thickening.

For the histological studies, samples were processed by routine techniques before embedding in paraffin wax. Sections were obtained from areas showing macroscopic damage, stained with haematoxylin and eosin and coded for blind examination by two pathologists (AS and FT). Both pathologists examined and scored all sections according to the presence of ulcerations, degree of inflammation, depth of the lesions, and fibrosis (Table I). The highest score obtained by each specimen was recorded for the statistical analysis.

INTRACOLONIC DIALYSIS

To measure luminal eicosanoid release, rats were given intracolonic dialysis for one hour, ${ }^{6}$ under ketamine anaesthesia $(100 \mathrm{mg} / \mathrm{kg}$, intraperitoneal). Dialysis bags were prepared using Visking seamless cellulose tubing (8/32, $6.3 \mathrm{~mm}$ diameter, $7 \mathrm{~cm}$ long; Medicell, London, UK) attached by a $8 \mathrm{~cm}$ rubber cannula to an external syringe. After inserting the entire cannula into the distal colon, the dialysis bag was filled with $1 \mathrm{ml}$ of dialysis solution, consisting of $0.3 \%$ bovine serum albumin in a solution of $120 \mathrm{mmol} / 1 \mathrm{NaCl}$ and $30 \mathrm{mmol} / 1 \mathrm{KHCO}_{3}$ (pH 7.9). One hour later, the fluid was withdrawn and stored at $-20^{\circ} \mathrm{C}$ until assayed.

EICOSANOID RADIOIMMUNOASSAYS

Eicosanoid concentrations in the dialysates were measured by specific radioimmunoassays for prostaglandin $E_{2}$, thromboxane $B_{2}$, and leukotriene $B_{4}$. Tritiated standards were purchased from Amersham International (Buckinghamshire, UK). Prostaglandin $\mathrm{E}_{2}$ antiserum was kindly donated by $\mathrm{Dr} J \mathrm{~A}$
Salmon (Wellcome Research Laboratories, Beckenham, UK). Antiserum for leukotriene $\mathrm{B}_{4}$ radioimmunoassay was purchased from Advanced Magnetic (Cambridge, MA). Samples were diluted $1: 10$ to $1: 25$ in assay buffer and measured without prior extraction and high performance liquid chromatography purification. ${ }^{6}$

PLASMA CONCENTRATIONS OF ANTIMICROBIAL DRUGS

Plasma concentrations of vancomycin were measured by a standard technique (Vancomycin Reagent Pak, Abbot, Abbot Park, IL) using a TD analyser (Abbot) in samples from rats that had been on imipenem $(50 \mathrm{mg} / \mathrm{kg}$ per day) plus vancomycin $(50 \mathrm{mg} / \mathrm{kg}$ per day) for four days given either by oral gavage $(n=4)$ or by intraperitoneal injection $(n=4)$. Blood samples were obtained one hour after the last dose of vancomycin.

\section{MICROBIOLOGICAL STUDIES}

Studies on faecal flora were performed seven days after induction of colitis in two controls, two imipenem ( $50 \mathrm{mg} / \mathrm{kg}$ per day, orally), two imipenem plus vancomycin $(50+50$ $\mathrm{mg} / \mathrm{kg}$ per day, orally), and two amoxicillin plus clavulanic acid $(160+40 \mathrm{mg} / \mathrm{kg}$ per day, enema) treated rats. In addition, two normal rats not given TNB were studied. Faecal specimens were obtained directly from the colonic lumen after laparotomy under anaesthesia (100 mg/kg ketamine) and kept in anaerobic containers. The samples were homogenised, diluted in normal saline, and appropriate dilution volumes were incubated under aerobic or anaerobic conditions. Aerobic media consisted of blood agar, blood agar with nalidixic acid, McConkey agar, CLED agar, Sabouraud agar, and mannitol agar. Anaerobic media consisted of lacquered blood agar enriched with hemin and vitamin $\mathrm{K}_{1}$, lacquered blood agar with phenyl ethanol, and agar aztreonam. Plates inoculated for obligate anaerobes were incubated in an anaerobic chamber for $48-72$ hours at $37^{\circ} \mathrm{C}$, and plates for aerobes in air at $37^{\circ} \mathrm{C}$. After incubation, colonies were enumerated and identified. Final counts of colonies are referred to as gram of dried faeces.

\section{STATISTICAL METHODS}

Results are presented as mean (SEM). The statistical difference between means was determined using one way analysis of variance for multiple comparisons and Student's $t$ test for single comparisons. Death rates were compared by the Fisher's exact test.

\section{Results}

EFFECT OF ANTIMICROBIALS ON THE ACUTE STAGE OF TNB COLITIS

On day 7 after TNB, control rats presented a thickened colonic wall with tight serosal 
TABLE II Effect of antimicrobials on the acute stage of $T N B$ colitis (day 7)

\begin{tabular}{lll}
\hline & \multicolumn{2}{l}{ Lesion scores } \\
\cline { 2 - 3 } Group & Macroscopic & Histological \\
\hline Control (2) & $6 \cdot 5(0 \cdot 8)$ & $7 \cdot 1(0 \cdot 6)$ \\
Amoxicillin/clavulanic acid (4) & $3 \cdot 8(0 \cdot 8) \dagger$ & $5 \cdot 3(0 \cdot 3) \dagger$ \\
$\quad$ by enema & & \\
Control (1) & $5 \cdot 5(0 \cdot 7)$ & $6 \cdot 8(0 \cdot 3)$ \\
Tobramycin (0) by enema & $5 \cdot 8(0 \cdot 7)$ & $6 \cdot 6(0 \cdot 4)$ \\
Control (1) & $7 \cdot 2(0 \cdot 7)$ & $8 \cdot 9(0 \cdot 3)$ \\
Impinenem (11)† orally & $7 \cdot 2(1 \cdot 6)$ & $8 \cdot 5(0 \cdot 5)$ \\
Control (0) & $7 \cdot 0(0 \cdot 8)$ & $7 \cdot 8(0 \cdot 5)$ \\
Vancomycin (3) orally & $5 \cdot 1(0 \cdot 9)$ & $7 \cdot 1(0 \cdot 6)$ \\
Control (1) & $5 \cdot 8(0 \cdot 7)$ & $6 \cdot 9(0 \cdot 3)$ \\
Metronidazole (0) by enema & $5 \cdot 1(0 \cdot 7)$ & $6 \cdot 1(0 \cdot 3)$ \\
Control (1) & $6 \cdot 8(0 \cdot 7)$ & $7 \cdot 5(0 \cdot 3)$ \\
Tobramycin plus vancomycin (1) & $5 \cdot 6(0 \cdot 6)$ & $7 \cdot 0(0 \cdot 2)$ \\
$\quad$ by enema & & \\
\hline
\end{tabular}

$\star$ Each group consisted initially of 15 rats. The death rate on day 7 after TNB is shown in brackets; $\nmid \mathrm{p}<0.05 v$ control group. Data shown as mean (SEM).

adhesions to surrounding organs. The mucosa seemed oedematous with transversal and longitudinal linear ulcerations that conferred on it a characteristic 'cobblestone' aspect. By light microscopy, large areas of necrotic mucosa, intense submucosal oedema, and transmural inflammation was recognised in most cases. Treatment with imipenem plus vancomycin or amoxicillin plus clavulanic acid significantly reduced macroscopic and histological lesion scores (see Fig 1 and Table II), but particularly scores related to the depth of the histologically damaged area, the thickening of the intestinal wall, and the presence of adhesions.

As Figure 1 shows, the way the antibiotic treatment was given was critical for a beneficial effect. The combination of imipenem with vancomycin acid was effective when given
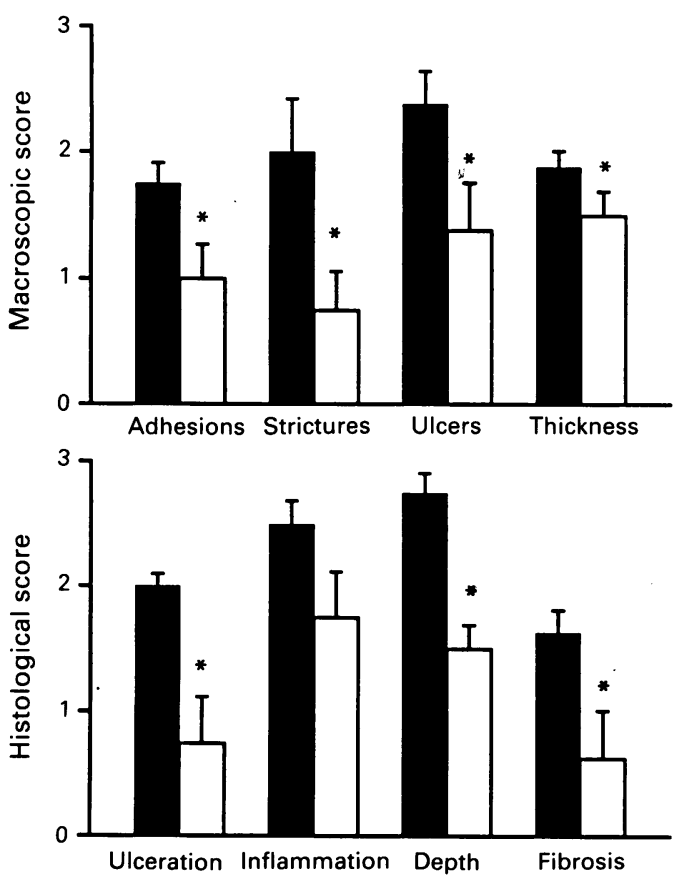

Figure 2: Effect of oral imipenem plus vancomycin on colonic lesion scores in the chronic stage of TNB induced colitis (day 21). Treated rats (open bars) showed significantly lower macroscopic and histological lesion scores than controls (solid bars). Differences in adhesions, strictures, ulceration, depth of the lesion, and fibrosis were particularly noticeable ( ${ }^{*} p<0,05 \mathrm{v}$ controls). orally or by enema, whereas intraperitoneal injection resulted in no significant effect (Fig 1). Both imipenem and vancomycin are poorly absorbed when given orally. Plasma concentrations of vancomycin were undetectable in four rats that received the drug by oral gavage. Therapeutic values of vancomycin could, however, be detected in plasma samples one hour after intraperitoneal injection of the drug (24 (7) $\mu \mathrm{g} / \mathrm{ml})$, even though this method yielded no beneficial effect on the colitis. Therefore, the beneficial effect of these antimicrobial drugs on colonic inflammation is unrelated to plasma bioavailability. Appropriate antimicrobial concentration in the colonic lumen seems to be critical for achieving a colonic therapeutic effect.

When imipenem plus vancomycin treatment was started 24 hours after induction of colitis, rats showed on day 7 lower macroscopic $(7 \cdot 1$ $(0 \cdot 8))$ and histological $(8 \cdot 4(0.5))$ lesion scores than controls $(9.8(0.3))$ and $9 \cdot 7(0.3)$, respectively, $\mathrm{p}<0.05)$. The effect was similar to that seen in rats pretreated with imipenem plus vancomycin (macroscopic score: 6.4 $(0 \cdot 7)$; histological score: $8 \cdot 1(0 \cdot 5)$. By day 7,3 of 15 rats had died in the control group, and 2 of 15 rats in each imipenem plus vancomycin group (pretreatment and post treatment groups).

Table II shows the macroscopic and histological scores of colonic lesions in rats that received other antimicrobials against different bacterial populations. Treatment with tobramycin enemas was directed against Gram negative bacilli. Tobramycin did not change the colonic lesion scores at day 7 after TNB. Oral treatment with imipenem, a nonabsorbable antibiotic active against most Gram positive cocci and Gram negative bacilli, and some anaerobes, also failed to modify the severity of the colonic lesion, but resulted in a significantly higher death rate than in control rats $(p<0.01)$. Vancomycin is a bactericidal agent active against Gram positive organisms including anaerobic species. This drug given orally reduced somewhat the macroscopic lesion scores but changes did not reach statistical significance. Treatment with metronidazole enemas, an agent active against anaerobic species and several protozoa, was not effective in reducing colonic lesions. Finally, treatment with tobramycin plus vancomycin enemas resulted in a mild reduction in lesion scores without statistical significance. This latter association is effective against Gram positive and Gram negative aerobic species but is not active against most anaerobic organisms.

EFFECT OF ANTIMICROBIALS ON THE CHRONIC STAGE OF TNB COLITIS

Broad spectrum antimicrobial drugs mitigated the progression of the colonic lesions to chronicity. As Figure 2 shows, treatment with imipenem plus vancomycin up to day 7 after TNB significantly reduced macroscopic and histological scores on day 21. Differences between controls and imipenem plus vanco- 

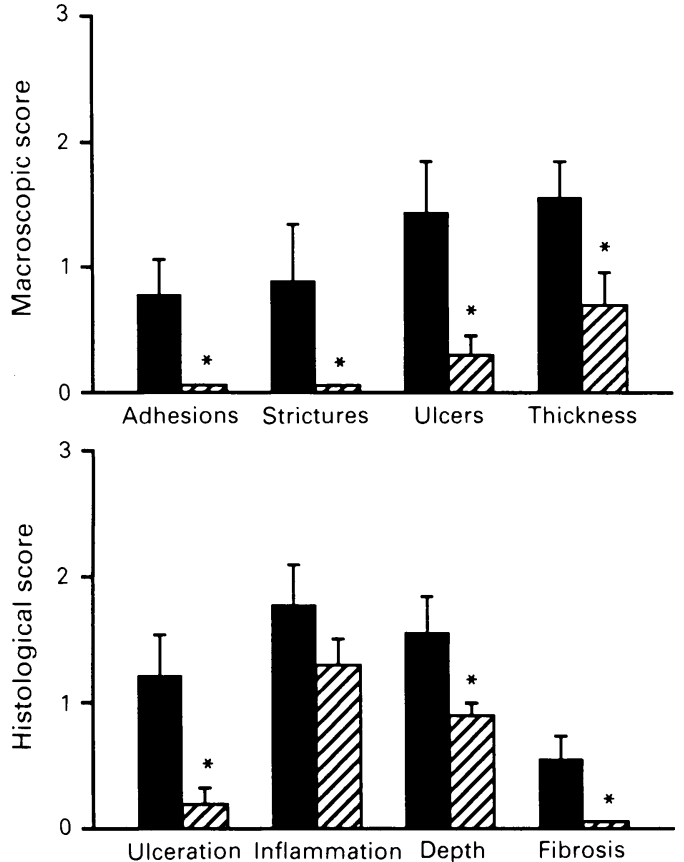

Figure 3: Effect of amoxicillin/clavulanic acid enemas on colonic lesion scores in the chronic stage of TNB induced colitis (day 21). Treated rats (hatched bars) showed significantly lower macroscopic and histological lesion scores than controls (solid bars). Adhesions, strictures, and fibrosis were absent in rats treated with amoxicillin/clavulanic acid enemas $\left({ }^{*} p<0.05 \mathrm{v}\right.$ controls).

mycin treated rats were particularly notable in ulceration, depth of the lesions, fibrosis, strictures, and adhesions. The death rate was similar in both groups: 5 controls and 4 imipenem plus vancomycin treated rats died before day 21 .

Figure 3 shows the effect of amoxicillin/clavulanic acid enemas given during the first week after TNB on the chronic colonic lesions on day 21 after TNB. Remarkably, no adhesions, fibrosis or strictures developed in these rats. These are the pathological features that are characteristic of the chronic stage of TNB induced colitis. Indeed, in TNB colitis obvious inflammation and ulcers only persist

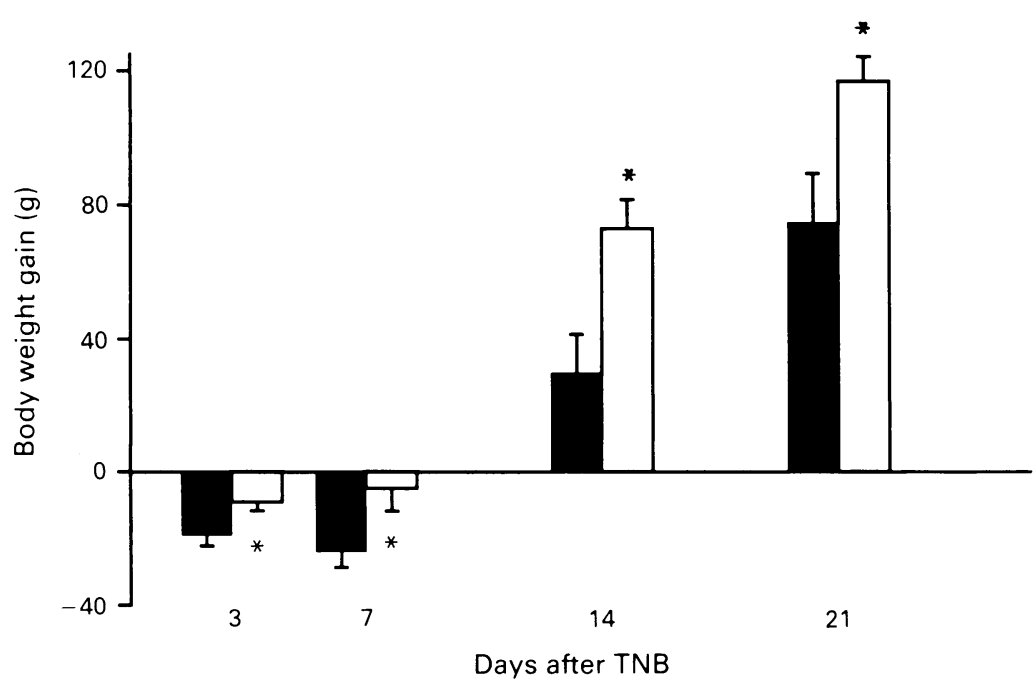

Figure 4: Induction of colitis by TNB was associated with a significant body weight loss that persisted up to day 7 in control rats (solid bars). In contrast, rats treated with oral imipenem plus vancomycin (open bars) showed only a mild body weight loss on day 3 after $T N B$, and by day 7 changes were not significant. Subsequent body weight gain was higher in treated rats than in controls $\left({ }^{*} p<0.05\right)$. beyond day 7 in dilated bowel segments proximal to strictures. It is therefore interesting to note that ulceration scores were higher in controls than in antibiotic treated rats. No mortality was seen in amoxicillin/clavulanic acid treated rats, and one rat from the control group died.

By light microscopy, microgranulomas were found in $38 \%$ of the control rats whereas none of the rats with amoxicillin/clavulanic acid and only one rat in the imipenem plus vancomycin group showed microgranulomas $(p<0.05$, Fisher's exact test).

Figure 4 shows the changes in body weight that occurred after induction of TNB colitis in control and in imipenem plus vancomycin treated rats. A net body weight loss was detected in every animal from the control group three days after the TNB challenge and continued during the acute stage of colitis peaking by day 7 . In contrast, antibiotic treated animals did not experience any significant weight loss. During the chronic stage of colitis, rats from the control group gradually recovered their lost body weight but, as shown by Figure 4, body weight gain remained significantly higher in antibiotic treated rats than in controls.

\section{COLONIC RELEASE OF INFI AMMATORY}

MEDIATORS

The release of inflammatory mediators by the colonic mucosa was measured in vivo by intracolonic dialysis. Figure 5 shows luminal eicosanoid release in controls and in rats treated orally with imipenem-vancomycin. Before the induction of colitis, a baseline luminal release of prostaglandin $\mathrm{E}_{2}$, thromboxane $B_{2}$, and leukotriene ${ }_{4}$ was detected in both experimental groups. By day 7 after TNB, luminal eicosanoid release had considerably increased in both groups of animals reflecting colonic inflammation. No significant differences between groups were apparent. By day 21 after TNB, however, luminal release of all three eicosanoids in antibiotic treated rats had decreased towards baseline values, whereas it remained significantly raised in control rats. These findings are consistent with our finding that during the chronic stage of TNB colitis inflammatory activity only persisted in control rats but not in imipenemvancomycin treated rats.

Similar results were obtained in rats treated with amoxicillin/clavulanic acid enemas. On day 21, luminal eicosanoid release in amoxicillin/clavulanic acid rats had returned to baseline, while control rats showed considerable release of inflammatory mediators significantly above baseline values.

\section{MICROBIOLOGICAL STUDIES}

Table III shows quantitative estimates of colony forming units after aerobic and anaerobic culture of stool samples. Analysis of faecal flora in normal rats not subjected to intracolonic TNB showed a considerable predominance of Lactobacillus spp among the 


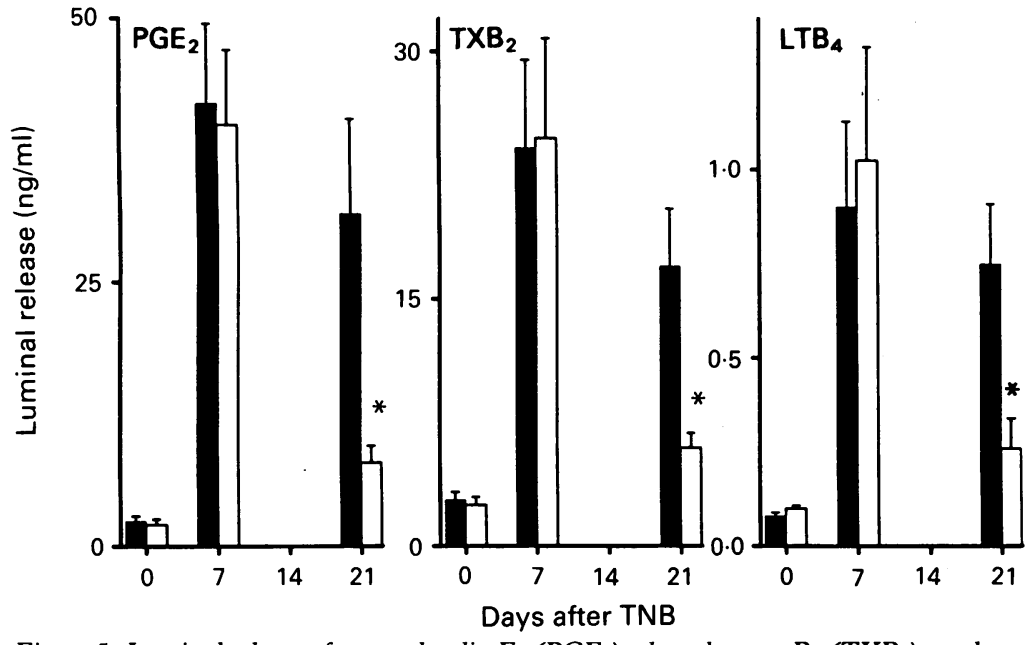

Figure 5: Luminal release of prostaglandin $E_{2}\left(P G E_{2}\right)$, thromboxane $B_{2}\left(T X B_{2}\right)$, and leukotriene $B_{4}\left(L T B_{4}\right)$ as measured by intracolonic dialysis in rats treated with oral imipenem plus vancomycin (open bars) and controls (solid bars). No differences were found between control and antibiotic treated rats on day 7 after TNB. On day 21 after TNB, however, colonic release of all three eicosanoids returned to baseline in antibiotic treated rats, while controls showed an enhanced release of the inflammatory mediators $\left({ }^{*} p<0.05 \mathrm{v}\right.$ controls). showed a $50 \%$ reduction in colony forming units of anaerobic species. In contrast with oral imipenem, amoxicillin/clavulanic acid enemas did not induce qualitative changes in the faecal flora but only reduced colony counts.

\section{Discussion}

The experiments described in this paper show that treatment with certain broad spectrum antibiotics reduces the severity of the colonic lesions induced by intracolonic administration of TNB. Acute colonic inflammation was not influenced by antibiotic treatment as shown by the intracolonic release of eicosanoids at day 7 after induction of colitis. The effect of broad spectrum antibiotics, however, was particularly manifest during the chronic stage of TNB colitis, as animals receiving antibiotic treatment rarely developed the characteristic pathological features seen in chronic colitis such as colonic strictures with proximal bowel dilatation, adhesions to surrounding tissues, fibrosis, and granulomas. Interestingly, during the chronic stage of colitis the intracolonic release of eicosanoids in antibiotic treated rates had returned to baseline, showing that the inflammatory process was not active at this stage. Taken together, these data suggest that intestinal decontamination using wide spectrum antibiotics inhibits the development of chronic inflammatory lesions. Instillation of TNB seems to be responsible for the initial inflammatory stimulus and the luminal colonic flora influences the chronic response. The normal colonic flora seems to play a key part in the progression of inflammatory colonic lesions to chronicity.

Two different antibiotic associations could prevent the development of chronic colitis, amoxicillin plus clavulanic acid and imipenem plus vancomycin. These drug regimens consist of chemically unrelated compounds that share antimicrobial activity against a broad spectrum of bacteria species. It is therefore unlikely that the beneficial effect of the drugs resulted from a pharmacological action unrelated to their antimicrobial activity. An interesting finding made in this study was that the association of imipenem plus vancomycin achieved a significant therapeutical effect in the prevention of chronic colitis, whereas neither agent had any beneficial effect when given independently.

TABLE III Faecal flora in TNB colitis

\begin{tabular}{|c|c|c|c|c|}
\hline \multirow[b]{2}{*}{ Normal rats } & \multicolumn{4}{|l|}{$T N B$} \\
\hline & Control & Imipenem & Imipenem/vancomycin & $\begin{array}{l}\text { Amoxicillin/clavulanic } \\
\text { acid }\end{array}$ \\
\hline $\begin{array}{l}\text { Aerobic culture } \\
7 \cdot 78-7 \cdot 79 \dagger \\
\text { Lactobacillus spp } \ddagger \\
\text { Streptococcus spp } \\
\text { E coli }\end{array}$ & $\begin{array}{l}7 \cdot 86-7 \cdot 88 \\
\text { E coli } \\
\text { Staphylococcus spp } \\
\text { Streptococcus spp }\end{array}$ & $\begin{array}{l}7 \cdot 91-7 \cdot 92 \\
\text { Candida spp } \neq \\
\text { E coli } \\
\text { Streptococcus spp }\end{array}$ & $\begin{array}{l}7 \cdot 91-7 \cdot 92 \\
\text { Candida spp } \neq \\
\text { E coli } \\
\text { Proteus mirabilis }\end{array}$ & $\begin{array}{l}7 \cdot 70-7 \cdot 74 \\
\text { E coli } \\
\text { Streptococcus spp } \\
\text { Proteus mirabilis }\end{array}$ \\
\hline $\begin{array}{l}\text { Anaerobic culture } \\
8 \cdot 10-8 \cdot 30 \\
\text { Bacteroides spp } \\
\text { Peptostreptococcus spp }\end{array}$ & $\begin{array}{l}7 \cdot 90-7 \cdot 92 \\
\text { Peptostreptococcus spp } \\
\text { Streptococcus intermedius } \\
\text { Clostridium spp } \\
\text { Bacteroides spp } \\
\text { Eubacterium spp }\end{array}$ & $\begin{array}{l}8 \cdot 22-8 \cdot 50 \\
\text { Bacteriodes spp } \ddagger \\
\text { Clostridium } \mathrm{spp} \\
\text { Peptostreptococcus spp }\end{array}$ & $<4 \S$ & $\begin{array}{l}7 \cdot 56-7 \cdot 65 \\
\text { Bacteroides spp } \\
\text { Clostridium } \mathrm{spp} \\
\text { Peptostreptococcus spp }\end{array}$ \\
\hline
\end{tabular}

^Includes facultative anaerobic bacteria; †colony forming units/g of dried faeces expressed as $\log _{10}$; $\neq$ predominant organism among the isolates; no anaerobes were isolated. 
Imipenem alone increased mortality. These findings suggested that the drugs were not primarily responsible for the anti-inflammatory effect, but that a broad spectrum bacterial decontamination was required to improve the colitis.

The route of administration was critical to achieve a therapeutic effect. Non-absorbable antibiotics such as imipenem and vancomycin were effective when given orally or by enema, whereas intraperitoneal injections were not effective. Only appropriate intracolonic concentrations of the antimicrobial drugs were associated with the anti-inflammatory effect. Therapeutic plasma concentrations of the antimicrobials were irrelevant. Again, these findings preclude the possibility of an antiinflammatory effect of the drugs unrelated to their antibiotic activity.

Selective antimicrobial treatment against Gram negative bacilli (tobramycin), Gram positive enterococci (vancomycin) or anaerobic species (metronidazole) had no effect on the colonic lesion scores. The association of tobramycin and vancomycin was also ineffective. Imipenem, a drug active against a wide range of Gram negative and Gram positive species including some anaerobes, intensified the colonic lesions and increased mortality induced by TNB. Our microbiological studies showed that treatment with imipenem only induced overgrowth of Bacteroides spp, particularly Bacteroides vulgatus. These results suggest that superinfection with Bacteroides vulgatus may exacerbate colonic lesions induced by TNB. Our findings are in agreement with previous studies by Onderdonk et al, ${ }^{15} 16$ that extensively showed the implication of Bacteroides vulgatus in the pathogenesis of carrageenin induced colitis in the guinea pig. In contrast with our findings, however, these authors saw in the guinea pig model that pretreatment with metronidazole prevents the induction of colitis by carrageenin feeding. ${ }^{17}$

The microbiological studies showed that treatment with imipenem plus vancomycin or amoxicillin/clavulanic acid significantly reduced the luminal content of bacteria species. In stool specimens from rats treated with imipenem plus vancomycin, aerobic and anaerobic bacteria were almost absent and had been replaced by overgrowth of Candida spp. Amoxicillin/clavulanic acid induced no important qualitative changes in the faecal flora, but reduced colony counts of anaerobes to $50 \%$ compared with controls. The fact that systemic antibiotics failed to prevent chronic inflammatory colitis suggests that dissemination of pathogens that could invade tissues is not a critical mechanism in the process of developing chronic lesions. Colitis induced by TNB does not evolve as a septic condition. Superinfection of TNB induced injury by normal flora, however, may play an important part, because when proliferation of the colonic flora is inhibited by appropriate intraluminal antibiotics a remarkable therapeutic action on colitis is achieved. Treatment with imipenem plus vancomycin was also effective when given
24 hours after the challenge with TNB, suggesting that the antibiotics enhanced repair mechanisms of established TNB induced lesions. Thus, commensal bacteria seem to be responsible for the chronicity of the inflammatory response to TNB. This sort of bacteria cannot cross epithelial barriers and spread beyond the injured areas, but they can proliferate on the surface of the lesions and hamper the resolution of the healing process. The precise mechanism by which they do so cannot be established from this study but our data clearly show that the presence of bacteria and their products perpetuates the inflammatory response. Perhaps, by sustaining the antigenic insult they stimulate the progression of the colitis towards chronicity.

The participation of luminal bacteria in the pathogenesis of other inflammatory conditions of the bowel has also been suggested in other animal models. Bacteria or bacterial products seem to be critical to the induction of mucosal ulcerations in the small bowel by indomethacin, as germ free rats develop minimal lesions ${ }^{18} 19$ and antibiotics decrease the severity of the ulcers. ${ }^{20}$ As mentioned, proliferation of anaerobes has been incriminated in the pathogenesis of experimental colitis by chronic feeding of sulphated polysaccharides such as carrageenin ${ }^{14-17}$ or dextran sulphate. ${ }^{21}$ This study provides significant evidence that the normal colonic flora plays a key part in the progression of inflammatory colonic lesions to chronicity, and hence illuminates the potential relevance of this often overlooked factor in human disease.

The study was supported by grant PB92-0733 from Dirección General de Investigación Científica y Técnica, Madrid, Spain.

1 Boughton-Smith NK, Wallace JL, Morris GP, Whittle BJR. The effect of anti-inflammatory drugs in a chronic model of inflammatory bowel disease in the rat. Br f Pharmacol 1988; 94: 65-72.

2 Morris GP, Beck PL, Herridge MS, Depew WT, Szewezuk MR, Wallace JL. Hapten-induced model of chronic inflammation and ulceration in the rat colon. Gastroenterology 1989; 96: 795-803.

3 Wallace JL, MacNaughton WK, Morris GP, Beck PL. Inhibition of leukotriene synthesis markedly accelerates healing in a rat model of inflammatory bowel disease. Gastroenterology 1989; 96: 29-36.

4 Allgayer $\mathrm{H}$, Deschryver $\mathrm{K}$, Stenson WF. Treatment with 16,16 '-dimethyl prostaglandin $\mathrm{E}_{2}$ before and after induc16,16 -dimethyl prostaglandin $\mathrm{E}_{2}$ before and after inducdecreases inflammation. Gastroenterology 1989; 96: 1290-300.

5 Rachmilewitz D, Simon PL, Schwartz LW, Griswold DE, Fondacaro JD, Wasserman MA. Inflammatory mediators of experimental colitis in rats. Gastroenterology 1989; 97: 326-37.

6 Vilaseca J, Salas A, Guarner F, Rodríguez R, Malagelada J-R. Participation of thromboxane and other eicosanoid synthesis in the course of experimental inflammatory colitis. Gastroenterology 1990; 98: 269-77.

7 Vilaseca J, Salas A, Guarner F, Rodriguez R, Martínez M, Malagelada JR. Dietary fish oil reduces progression of chronic inflam. 1990; 31: 539-44.

8 Grisham MB, Volkmer C, Tso P, Yamada T. Metabolism of trinitrobenzene sulfonic acid by the rat colon produces reactive oxygen species. Gastroenterology 1991; 101: reactive

9 Pons L, Droy-Lefaix MT, Buerno L. Leukotreine $\mathrm{D}_{4}$ participates in colonic transit disturbances induced by intracolonic administration of trinitrobenzene sulfonic acid in rats. Gastroenterology 1992; 102: 149-56.

10 Yamada T, Marshall S, Specian RD, Grisham MB. A comparative analysis of two models of colitis in rats. Gastroenterology 1992; 102: 1524-34.

11 Little JR, Eisen HN. Preparation and characterization of antibodies specific for the 2,4,6-trinitrophenyl group. Biochemistry 1966; 5: 3385-95. 
12 Kunin S, Gallily R. Recognition and lysis of altered self cells by macrophages, a modification of target cells by $2,4,6$ trinitrobenzene sulfonic acid. Immunology 1983; 121: 1711-8.

13 Sartor RB, Cromartie WJ, Powell D, Schwab JH. Granulomatous enterocolitis induced in rats by purified bacterial cell wall fragments. Gastroenterology 1985; 89: 587-95.

14 Onderdonk AB, Bartlett JG. Bacteriological studies of experimental ulcerative colitis. Am f Clin Nutr 1979; 32: 258-65.

15 Onderdonk AB, Cisneros RL, Bronson RT. Enhancement of experimental ulcerative colitis by immunization with of experimental ulcerative colitis by immunization

16 Onderdonk AB, Steeves RM, Cisneros RL, Bronson RT. Adoptive transfer of immune enhancement of experimental ulcerative colitis. Infect Immun 1984; 46: 64-7.

17 Onderdonk AB, Hermos JA, Dzink JL, Bartlett JG.
Protective effect of metronidazole in experimental ulcerative colitis. Gastroenterology 1978; 74: 521-6.

18 Robert A, Asano T. Resistance of germfree rats to indomethacin induced intestinal lesions. Prostaglandins 1977; 14: 333-41.

19 Davis SW, Holt LC, Sartor RB. Luminal bacteria and bacterial polymers potentiate indomethacin-induced intestinal injury in the rat. Gastroenterology 1990: 98: $444 \mathrm{~A}$.

20 Kent TH, Cardelli RM, Stamier FW. Small intestinal ulcers and intestinal flora in rats given indomethacin. $\mathrm{Am} \mathcal{J}$ Pathol 1969; 34: 237-45.

21 Okayasu I, Hatakeyama $S$,. Yamada $M$, Ohkusa $T$, Inagaki $Y$, Nakaya R. A novel method in the induction of reliable experimental acute and chronic ulcerative colitis in mice. Gastroenterology 1990; 98: 694-702. 